\title{
Success Rate of Three Capping Materials used in Pulpotomy of Primary Molars: A Randomized Clinical Trial
}

Randa Youssef Abd Al Gawad ( $\square$ randa.youssef@yahoo.com )

Cairo University https://orcid.org/0000-0003-0123-8574

Rasha Mohamed Hatem

Faculty of Dentistry, Cairo University

Research article

Keywords: Dental materials, FC, MTA, NHA, Primary molars, Pulpotomy

Posted Date: March 17th, 2020

DOI: https://doi.org/10.21203/rs.3.rs-17478/v1

License: (c) (i) This work is licensed under a Creative Commons Attribution 4.0 International License.

Read Full License 


\section{Abstract}

Background: Carious primary molars, symptomless, or with reversible pulpitis are most frequently treated with pulpotomy to maintain arch integrity, otherwise they would be extracted. The present study was conducted to assess clinically and radiographically the success rate of three capping materials: Nanohydroxyapatite (NHA), Mineral Trioxide Aggregate (MTA) and Formocresol (FC) in pulpotomy of primary molars.

Methods: A clinical trial was carried out on healthy, four to eight years old children, with 72 second primary molars indicated for pulpotomy. Molars were divided into 3 equal groups (24 teeth each) designated to NHA (group 1), MTA (group 2) and FC (group 3) as pulp medicaments. Treated teeth were finally restored with stainless steel crowns. Subjects were monitored clinically and radiographically at three, six- and twelve-months time intervals. The difference in success rate between groups at the same time point was evaluated using Chi square test. Significant level was set at $p<0.05$. Statistical analysis was performed using a commercially available software program SPSS version 21 .

Results: The highest overall success was recorded in MTA group (90.5\%), followed by FC group (76.2\%). The least overall success was found in NHA group (72.2\%). Statistical analysis of data revealed that the difference between the three groups was not statistically significant.

Conclusions: MTA is still the material of choice for pulpotomy in primary molars. Further studies are recommended to evaluate the use of NHA as a potential alternative to MTA.

Trial registration: This trial was registered on Clincal.Trial.gov (https://clinicaltrials.gov.), on February 8, 2019 (Retrospectively registered). The protocol ID is 181053 . The Identifier is NCT03833557.

\section{Background}

Pulpotomy is a procedure that is most frequently used in treatment of primary teeth. It involves complete removal of coronal pulp tissue in primary teeth with extensive caries adjacent to the pulp leaving the radicular pulp vital ${ }^{1}$.

The radicular pulp tissue is then, covered with a capping material such as, Formocresol (FC), that fixes and mummifies the radicular pulp to become non vital and nonfunctional (Devitalization), Ferric Sulfate, (Preservation) where it causes minimal reversible changes in the orifice pulp tissue while preserving the vitality and normal histologic appearance of the entire radicular pulp, Mineral trioxide aggregate (MTA) and Nanohydroxyapatite (NHA), that induce Dentin Bridge formation (Regeneration). ${ }^{2-4}$

In the past years, FC was the most commonly used pulp medicament for primary teeth as it is bactericidal, easy to use and has fixative properties. ${ }^{3-5}$ However, alternative techniques and new biocompatible and bio-inductive pulp capping agents have been developed to overcome the toxicity, 
mutagenicity, and potential carcinogenicity of FC in humans ${ }^{4}$; shifting the procedure from preservation to regeneration. ${ }^{3}$

Mineral trioxide aggregate is a fine hydrophilic powder formed of tricalcium silicate, tricalicum aluminate, tricalcium oxide, silicate oxide and bismuth oxide. ${ }^{6}$ It is a biocompatible material promoting hard tissue formation, without any cytotoxic effect. ${ }^{6,7}$

It is currently used in pulpotomy of primary molars, pulp capping, apexification, sealing of root perforations with a high rate of success; however, MTA has long setting time, poor handling properties and unfavorable rate of resorption. ${ }^{5,8}$

Hydroxyapatite is a remineralizing material that is used in restorations, regeneration and reconstruction of bony defects as it is biocompatible, resemble mineral tissues, antibacterial and has low solubility. ${ }^{8}$

The nanotechnology has improved the properties of HA giving rise to a material that gained great attention due to its higher mechanical properties, higher biocompatibility and greater contact area. This material is the $\mathrm{NHA}{ }^{9}$

Therefore, prospective clinical studies are necessary to qualify NHA versus MTA as alternative materials to $\mathrm{FC}$ in pulpotomy of primary teeth. The purpose of this clinical trial was to assess clinically and radiographically the success rate of NHA and MTA used as pulpotomy agents in primary molars and compare them to that of FC.

\section{Methods}

\section{Ethics approval:}

Ethical approval for the research protocol was obtained from the Research Ethics Committee, Faculty of Dentistry, Cairo University with the reference code (18 10 53).

\section{Study design:}

The present study was a parallel, randomized clinical trial (RCT) with 1:1:1 allocation ratio; conducted in Pediatric Dentistry and Dental Public Health Department, Faculty of Dentistry, Cairo University. In this study, patients, their guardians and statistician were blinded.

\section{Sample size:}

According to Godhi et al ${ }^{3}$ and Olatosi et al ${ }^{10}$, a sample size of 72 second primary molars (including dropouts) was determined using G*power Program (University of Düsseldorf, Düsseldorf, Germany).

\section{Subjects:}


The study population included four to eight years old, apparently healthy and cooperative patients who presented at the Pediatric Dental Clinic, Faculty of Dentistry, Cairo University and had deep carious mandibular second primary molars indicated for pulpotomy. Written consent was obtained from the parent/guardian after a comprehensive explanation of the study protocol. Personal, medical, dental history and clinical evaluation were obtained from all patients participating in this study.

\section{The criteria for inclusion in this study were:}

- Pulp exposure due to caries removal or after a traumatic pulp exposure. ${ }^{11}$

- No history of spontaneous pain, tenderness to percussion, tooth mobility.

- No clinical evidence of pulpal inflammation or degeneration, such as history of swelling or presence of sinus tract.

- Restorable teeth.

- Absence of radiographic evidence of internal or external root resorption, pulpal calcification, or osseous disease (periapical or furcation infection).

\section{On the other hand, teeth were excluded if:}

- Evidence of necrosis after access cavity preparation.

- Hemostasis could not be achieved within three min after direct contact with a wet cotton pellet, after removal of coronal pulp tissue.

\section{Randomization \& allocation concealment:}

Simple randomization was done, to allocate the molars, using computer sequence generation (www.random.org) by the second investigator with 1:1:1 allocation ratio into three groups $(n=24)$ based on the pulp capping materials. Group 1: NHA (Straumann Bone Ceramic, Switzerland), Group 2: MTA (Angelus- Londrina, Brazil), and Group 3: FC (Formacresol, Prevest DenPro Limited, India) as pulp medicaments. Allocation concealment was done using opaque envelopes.

\section{Sequence generation:}

Sequence generation was done for the molars number (1 to 72$)$ using computer sequence generation (www.random.org). The sequence generator icon was selected from the home page, the sample size was specified, and the format in two columns was ordered. The result was then copied to group 1, group 2 and group 3, with randomized molars' numbers (24 numbers in each group).

\section{Allocation Concealment Mechanism:}

Each of the 72 papers numbered from 1 to 72 , was individually packed by the second investigator in an opaque envelope after folding each paper eight folds. Each patient was asked to pick an envelope, after 
their enrollment in the study and before the beginning of treatment. Numbers in the envelopes determined the group assigned for each molar.

The study was registered with clinicaltrials.gov under the title: Success Rate of Three Capping Materials: A randomized Clinical Trial, with an identifier: NCT03833557.

\section{Procedures:}

Preoperative periapical radiograph using periapical film size two (Speed D Film, Kodak, US) was taken for the molars considered for treatment; for proper radiographic diagnosis.

The first investigator performed the pulpotomy procedure. Under local anesthesia and rubber dam isolation, caries was removed and deroofing of the pulp chamber was performed using a \#330 highspeed carbide bur mounted in a water-cooled high-speed turbine. The coronal pulp tissue was amputated using a sterile sharp spoon excavator. The pulp chamber was irrigated with normal saline. Pulp hemostasis was achieved using a sterile wet cotton pellet applied for two to three minutes.

In Group 1: NHA was used according to the manufacturer's instructions; it was mixed with saline and was placed over the pulp stumps using amalgam carrier and condenser.

In Group 2: MTA powder was mixed with sterile water in a 3:1 powder/water ratio, according to the manufacturer's instructions to obtain a thick creamy paste, placed using a messing gun and compacted against the pulp orifices with a condenser over a moist cotton pellet.

In Group 3: After blood clot formation, a sterile cotton pellet moistened with FC (squeezed twice) was placed over the radicular pulp for 5 minutes and then removed. A thick mix of Zinc Oxide Eugenol (ZOE) paste was placed over the FC fixed tissue using a cement spatula and condensed as previously mentioned.

All molars were finally restored with stainless steel crowns (3M, ESPE, Unitek, US) cemented with GI cement. An immediate postoperative radiograph using periapical film size two was taken. Oral hygiene measures were given to the patients.

\section{Clinical \& radiographic evaluation:}

All treated patients were followed up by the other investigator at three, six and twelve months after the pulpotomy for clinical and radiographic evaluation. Blinding was not feasible as NHA appears radiolucent in the radiographs.

Molars were judged as clinically successful if they met the following criteria: Absence of sensitivity, pain, tenderness to percussion, abscess, fistula or tooth mobility. Radiographic failure was defined according to radiographic failure score ${ }^{12}$, Table (1).

\section{Statistical analysis:}


For the three groups, clinical and radiographic findings at three, six and twelve months postoperatively were assessed. The difference in success rate between groups at the same time point was evaluated using Chi square test. Significant level was set at $\boldsymbol{p}<0.05$. Statistical analysis was performed using a commercially available software program SPSS version 21 (Chicago, IL, USA).

\section{Results}

A Consort diagram showing the study protocol up to the 12 months follow-up is presented in Fig. (1). Throughout all the follow up time points, MTA was the most successful material (90.5\%) followed by FC group (76.2\%). The least overall success was found in NHA group (72.2\%). Clinical and radiographic findings, as well as, radiographic Failure score in the three groups, throughout the whole study period are illustrated in Table (2-5), Fig. (2-4).

\section{Discussion}

The present clinical trial is a prospective clinical study for vital pulpotomy in primary molars using NHA, MTA and FC. Nanohydroxyapatite was used in the present study, as it is a relatively new bioactive and biocompatible promising material with osteoconductive and dentinogenic properties that make it a potential pulpotomy agent. It has high mechanical strength, great contact area and highly similar to the mineral tissues. ${ }^{8}$ It has many clinical applications in restoration and regeneration of bony defects but few limited studies have evaluated its efficiency as vital pulp capping agent. ${ }^{13}$

Mineral Trioxide Aggregate is a highly successful biocompatible regenerative pulp dressing material that has successfully replaced FC as a pulpotomy medicament for primary teeth. ${ }^{14,15}$ Unfortunately, its long setting time, poor handling properties and its slow rate of resorption are main disadvantages that cause its poor clinical acceptance. 4,16,17 These drawbacks are considered as advantages offered by NHA.

Formocresol was considered, in the near past, as the gold standard dressing agent for pulpotomy of primary teeth due to its long-term clinical use and success. Also, it is a cheap material compared to other materials. However, its toxicity, mutagenicity and devitalizing effect on the remaining radicular pulp tissue are of great concern. ${ }^{18}$

Children aging between four to eight years old were selected to enroll in the present trial to ensure their cooperation and to avoid physiologic root resorption in elder ones. ${ }^{4,19}$.

This study was a RCT; which is considered the gold standard for a clinical trial with the highest level of evidence. Selection bias was minimized by randomization. The three groups were similar, as much as, possible in all factors except for the treatment to which each group was exposed. ${ }^{20}$

Only mandibular molars were included in the present study, because they show more accurate radiographic interpretation than maxillary ones, due to minimal overlapping of permanent tooth buds 
over the roots of primary molars, and also, they offer better visualization. ${ }^{4,21}$

Pulpotomy procedures were performed by the same operator for better standardization. All pulpotomized teeth were finally restored with stainless steel crowns as they represent the most effective long-term restoration that strengthen the pulpotomized teeth and protect them from fracture and also ensure optimum coronal seal to promote pulp healing. ${ }^{1,22-24}$

An immediate postoperative radiograph was obtained to document treatment quality and serve as baseline record. Radiographic examination was performed using periapical radiographs that show clearly both of the periradicular and inter-radicular areas. It is the best method to detect root resorption, periapical tissue status, periodontal status, osseous defects and any changes in the surrounding structures. ${ }^{4,25}$

Furcation radiolucency in follow up radiographs was recorded by radiographic score, ${ }^{12}$ that gives a number denoting the quantity of bone loss to facilitate the comparison between groups.

The results of the present trial, through the whole study period, showed an overall success rate both clinically and radiographically for the three materials, with the highest success in MTA group (90.5\%) followed by FC group (76.2\%) and the least success rate was found in NHA group (72.2\%).

The current results are in accordance with those of Ghoniem et $\mathrm{al}^{26}{ }^{26}$ comparing the outcomes of grey MTA and diluted FC in primary molars pulpotomies over 48 months. They reported radiographic success rate of $95 \%$ for MTA and $80 \%$ for diluted FC.

Also, a systematic review was carried out to assess the effect of different techniques and medicaments of pulp treatment in primary teeth with extensive decay and evidence proved that MTA is the most efficient pulp medicament after pulpotomy in primary teeth. ${ }^{27}$

Another randomized controlled trial was conducted by Jamali et $\mathrm{al}^{28}$ to compare the efficacy of 3Mixtatin (a combination of simvastatin and 3Mix antibiotic) with MTA and FC for the pulpotomy of primary molars for 24 months. The overall success rate was $88.1 \%$ for MTA, $78.9 \%$ for FC and $90.5 \%$ for 3 Mixtatin group.

The findings of the current study also coincide with those found by Olatosi et al, ${ }^{10}$ who compared the efficacy of white MTA and FC as pulpotomy materials on primary molars over a period of 12 months, and reported high success rates both clinically and radiographically $(100 \%$ and $96 \%$ respectively in the MTA group and $81 \%$ in FC group), with no statistically significant difference between the two agents.

Additionally, the results of the present study are confirmed by Godhi et al, ${ }^{3}$ when they compared the clinical and radiographic efficacy of MTA and FC as pulpotomy medicaments in the treatment of carious primary molars over a period of 12 months. Both groups showed $100 \%$ clinical success throughout the whole study period, while the radiographic success rates of FC and MTA were $88 \%$ and $96 \%$, respectively. 
Furthermore, the results of the current study were confirmed by a systemic review and meta-analysis evaluating the outcomes of different pulp therapy techniques in primary teeth and the highest level of success and quality of evidence was for the pulpotomy using MTA and FC for the treatment of deep caries in primary teeth after 24 -months follow up period. ${ }^{29}$

On the other hand, the clinical success rate of NHA in the present study disagrees and is lower than what was previously reported by Adlakha et al, ${ }^{30}$ who evaluated the success and efficacy of HA crystals and Glutaraldehyde as pulpotomy agents both clinically and radiographically. In the HA treated molars $(n=$ 15), all treated teeth in the 6 months follow-up period were clinically successful. However, the radiographic findings showed a success of $80.33 \%$. The authors attributed the high success rates to proper case selection, precise technique procedures and also to the high biocompatibility, alkalinity, regenerative power, and excellent sealing ability of the new regenerative materials ${ }^{31}$ and added that these results could be explained on histologic basis by Haghgoo et al, ${ }^{8}$ who found that NHA may act as chemical cell absorbent that facilitates the invasion of osteoblasts, however, Adlakha et al, ${ }^{30}$ used two different types of NHA crystals with smaller crystal length and diameter by $7 \mathrm{~nm}$ and lesser degree of crystallization by $20 \%$ than that used in the current study; which may have greater penetration, better contact with pulp tissue and better sealing ability.

\section{Conclusion}

Based on this study results, we may conclude that MTA is still the material of choice for pulpotomy in primary molars. Further studies are highly required to evaluate the use of NHA as a potential alternative to MTA.

\section{Abbreviations}

FC

Formocresol

$\mathrm{GI}$

Glass lonomer

HA

Hydroxyapatite

MTA

Mineral Trioxide Aggregate

$\mathrm{NHA}$

Nanohydroxyapatite

RCT

randomized controlled trial

ZOE

Zinc Oxide Eugenol 


\section{Declarations}

The reporting of this manuscript adheres to CONSORT guidelines for reporting clinical trials

\section{- Ethics approval and consent to participate:}

Ethical approval for the research protocol was obtained from the Research Ethics Committee, Faculty of Dentistry, Cairo University (code 1810 53).

Written consent was obtained from the parent/guardian after a comprehensive explanation of the study protocol.

\section{- Consent for publication:}

We confirm that this manuscript has not been published elsewhere and is not under consideration by another journal. All authors have approved the manuscript and agree with submission to BMC Oral Health.

\section{- Availability of data and materials:}

The databases used and /or analyzed during the current study are available from the corresponding author on reasonable request.

\section{- Competing interests:}

This article is original and free of conflict of interests. No funds were taken from any institution or company.

\section{- Funding:}

This research is totally self -funded.

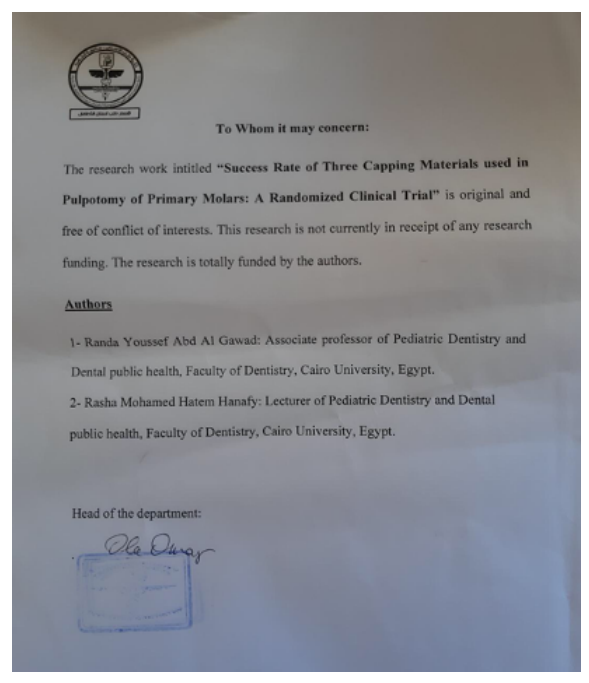

- Authors' Contributions: 
R.Y.A and R.M.H conceived the ideas; R.Y.A and R.M.H collected the data; R.Y.A performed the clinical procedure, R.M.H followed up the cases and led the writing, both authors revised the manuscript.

- Acknowledgements:

Great appreciation is directed to children and their parents who participated in this study.

\section{- Authors' information:}

1.Randa Youssef Abd Al Gawad: Associate professor of Pediatric Dentistry and Dental public health, Faculty of Dentistry, Cairo University -Egypt.

Mobile number: +201222272010

E-mail: randa.youssef@yahoo.com

Address: 301 venos, Royal city Sheikh Zaid, Egypt.

2.Rasha Mohamed Hatem Hanafy: Lecturer of Pediatric Dentistry and Dental public health, Faculty of Dentistry, Cairo University, Egypt.

Mobile number: +201001670222

E-mail: r_mhatem@hotmail.com

\section{References}

1. AAPD. Guideline on pulp therapy for primary and young permanent teeth. Reference Manual, 2014; 37:244-25.

2. McDonald RE, Avery DR, Dean JA. Dentistry for the Child and Adolescent. 8th Ed. Mosby, St Louis, 2014; 406-8.

3. Godhi B, Sood PB, Sharma A. Effects of mineral trioxide aggregate and formocresol on vital pulp after pulpotomy of primary molars: An in vivo study. Contemp Clin Dent, 2011; 2(4): 296-301.

4. Fouad W, Youssef R. Clinical and radiographic assessment of vital pulpotomy in primary molars using mineral trioxide aggregate and a novel bioactive cement. Egypt Dent J, 2013; 59(7): 3003-13.

5. Erdem AP, Guven Y, Balli B, Ilhan B, Sepet E, Ulukapi I, et al. Success rates of mineral trioxide aggregate, ferric sulfate and formocresol pulpotomies: a 24-month study. Pediatr, 2011; 33: 165-70.

6. Torabinejad M, Chivian N. Clinical applications of Mineral Trioxide Aggregate. J Endod, 1999; 25:197205.

7. Peng L, Ye L, Tan H, Zhou X. Evaluation of the formocresol versus mineral trioxide aggregate primary molar pulpotomy: a meta-analysis. Oral Surg Oral Med Oral Pathol Oral Radiol Endod, 2006; 102: 404. 
8. Haghgoo R, Asgary S, Abbas FM, Hedeshid RM. Nano-hydroxyapatite and calcium-enriched mixture for pulp capping of sound primary teeth: a randomized clinical trial. Iran Endod J, 2015; 10(2): 10711.

9. Haghgoo R, Ataie M, Tavassoli S, Kameli S, Rahimian S. The effect of various amounts of nanohydroxyapatite on the mechanical properties and remineralization of a fissure sealant. J Dent, 2012; 30(3):184-91.

10. Olatosi OO, Sote EO, Orenuga 00 . Effect of mineral trioxide aggregate and formocresol pulpotomy on vital primary teeth: A clinical and radiographic study. Niger J Clin Pract, 2015; 18(2):292-6.

11. American Academy of Pediatric Dentistry. Guideline on pulp therapy for primary and immature permanent teeth. Reference Manual, 2019; 32:194-201.

12. Memarpour M, Fijan S, Asgary S, Keikhaee M. Calcium-enriched mixture pulpotomy of primary molar teeth with irreversible pulpitis. A clinical study. Open Dent J, 2016; 10(1), 43-9.

13. Zarrabi M, Jaridi M, Jafarian A, Joushan B. Tenascin in human tooth pulp capped with mineral trioxide aggregate and a novel endodontic cement. J Endod, 2011; 27(12):1613-6.

14. Naik S, Hegde AM. Mineral trioxide aggregate as a pulpotomy agent in primary molars: An in vivo study. J Indian Soc Pedod Prev Dent, 2005; 23:13-6.

15. Ribeiro DA, Matsumoto MA, Duarte MA, Marques ME, Salvadori DM. Ex vivo biocompatibility tests of regular and white forms of mineral trioxide aggregate. Int Endod J, 2006; 39:26-30.

16. Ford TR, Torabinejad M, Abedi HR, Bakland LK, Kariyawasam SP. Using mineral trioxide aggregate as a pulp capping material. J Am Dent Assoc, 1996; 127:1491-4.

17. Torabinejad M, Chivian N. Clinical applications of mineral trioxide aggregate. J Endod, 1999; 25: 19705.

18. Seale S. Vital Pulp Therapy for the Primary Dentition. ADTS, 2010; 331-51.

19. Neamatollahi $\mathrm{H}$, Tajik A. Comparison of clinical and radiographic success rates of pulpotomy in primary molars using Formocresol, Ferric Sulfate and Mineral Trioxide Aggregate (MTA). J Dent, 2006; 3(1): 6-14.

20. Hopewell S. The quality of reports of randomized trials in 2000 and 2006. BMJ, 2010; 340.

21. Mohammad G, Jerin, F, Jebin, S. Pulpal Diagnosis of Primary Teeth: Guidelines for Clinical Practice. BJDRE, 2012; 2(2): 65-6820.

22. Farsi N, Alamoudi N, Balto K, Mushayt A. Success of mineral trioxide aggregate in pulpotomized primary molars. J Clin Pediatr Dent, 2005; 29: 307-11.

23. Moretti ABS et al. The effectiveness of mineral trioxide aggregate, calcium hydroxide and formocresol for pulpotomies in primary teeth. Int Endod J, 2008; 41(7): 547-55.

24. Carrotte, PV, Waterhousem PJA. Clinical guide to endodontics - update part 2. BDJ, 2009; 206(3): $133-9$.

25. 25. Kumar S, Kirandeep KA, Udupa H. Different Radiographic Modalities Used for Detection of Common Periodontal and Periapical Lesions Encountered in Routine Dental Practice. J Dent Oral 
Hyg, 2014; 2(5): 1-11.

26. Ghoniem N, Vaidyanathan V, Zealand CM, Sushynski JM, Mettlach SM, Botero TM et al. Mineral trioxide aggregate and diluted formocresol pulpotomy: Prospective and retrospective study outcomes, $2018 ; 100(4): 40-65$.

27. Smaïl-Faugeron V, Glenny AM, Courson F, Durieux P, Muller-Bolla M, Fron Chabouis H. Pulp treatment for extensive decay in primary teeth. Cochrane Database Syst Rev, 2018;5(5):CD003220.

28. Jamali Z, Alavi V, Najafpour E, Aminabadi NA, Shirazi S. Randomized controlled trial of pulpotomy in primary molars using MTA and formocresol compared to 3Mixtatin: A novel biomaterial. J Clin Pediatr Dent, 2018; 42(5):361-6.

29. Coll JA, Seale NS, Vargas K, Marghalani AA, Al Shamali S, Graham L. Primary tooth vital pulp therapy: a systematic review and meta-analysis. Pediatr Dent , 2017;15;39(1):16-123.

30. 30. Adlakha VK, Chandna P, Joshi JL, Thomas AM, Singh N. A comparative evaluation of hydroxyapatite crystals and glutaraldehyde as agents for pulpotomy in deciduous molars. Int $\mathrm{J}$ Clin Pediatr Dent, 2009; 2(1): 13-22.

31. El Meligy O, Allazzam S, Alamoudi N. Comparison between biodentine and formocresol for pulpotomy of primary teeth: A randomized clinical trial. QI, 2016; 1-10.

\section{Tables}

Table 1: Radiographic evaluation according to radiographic failure score

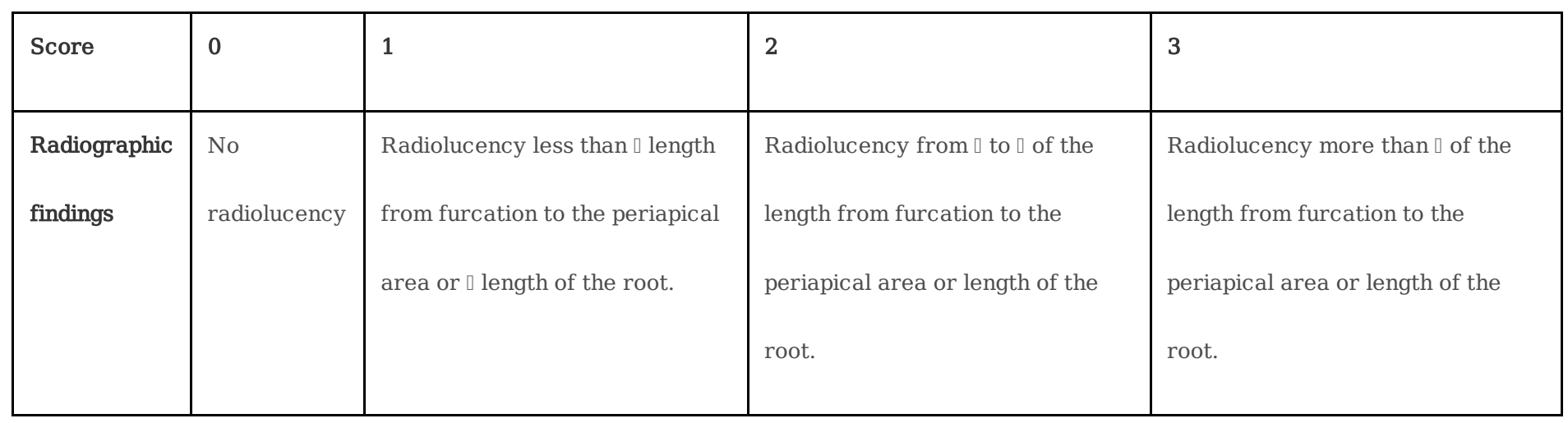

Table 2: Clinical success rate for the three groups during different follow up periods 


\begin{tabular}{|c|c|c|c|c|c|c|c|c|c|c|c|c|}
\hline \multirow[t]{2}{*}{ Time } & & \multicolumn{3}{|c|}{ NHA } & \multicolumn{3}{|c|}{ MTA } & \multicolumn{3}{|c|}{ FC } & \multirow[t]{2}{*}{$\mathrm{X} 2$} & \multirow[t]{2}{*}{$p^{*}$, Chi-square test } \\
\hline & & No & Yes & $F$ & No & Yes & $\mathrm{F}$ & No & Yes & $F$ & & \\
\hline \multirow[t]{4}{*}{3 months } & Pain & $17(94.4)$ & $1(5.6)$ & 0 & $21(100)$ & 0 & 0 & $21(100)$ & 0 & 0 & 2.37 & 0.66 \\
\hline & Mobility & $18(100)$ & 0 & 0 & $21(100)$ & 0 & 0 & $21(100)$ & 0 & 0 & 0 & 1 \\
\hline & Swelling & 18(100) & 0 & 0 & $21(100)$ & 0 & 0 & $21(100)$ & 0 & 0 & 0 & 1 \\
\hline & Sinus/fistula & 18(100) & 0 & 0 & $21(100)$ & 0 & 0 & $21(100)$ & 0 & 0 & 0 & 1 \\
\hline \multirow[t]{4}{*}{6 months } & Pain & $16(88.8)$ & $1(5.6)$ & $1(5.6)$ & $21(100)$ & 0 & 0 & $21(100)$ & 0 & 0 & 4.83 & 0.31 \\
\hline & Mobility & $17(94.4)$ & 0 & $1(5.6)$ & $21(100)$ & 0 & 0 & $21(100)$ & 0 & 0 & 2.37 & 0.67 \\
\hline & Swelling & $17(94.4)$ & 0 & $1(5.6)$ & $21(100)$ & 0 & 0 & $21(100)$ & 0 & 0 & 2.37 & 0.67 \\
\hline & Sinus/fistula & $17(94.4)$ & 0 & $1(5.6)$ & $21(100)$ & 0 & 0 & $21(100)$ & 0 & 0 & 2.37 & 0.67 \\
\hline \multirow[t]{5}{*}{12 months } & Pain & $13(72.2)$ & 0 & 5 & $21(100)$ & 0 & 0 & $21(100)$ & 0 & 0 & 12.7 & $0.013^{*}$ \\
\hline & Mobility & $13(72.2)$ & 0 & 5 & $21(100)$ & 0 & 0 & $21(100)$ & 0 & 0 & 12.7 & 0.013* \\
\hline & Swelling & $13(72.2)$ & 0 & 5 & $21(100)$ & 0 & 0 & $21(100)$ & 0 & 0 & 12.7 & 0.013* \\
\hline & Sinus/fistula & $13(72.2)$ & 0 & 5 & $21(100)$ & 0 & 0 & $21(100)$ & 0 & 0 & 12.7 & $0.013^{*}$ \\
\hline & & & & (27.8) & & & & & & & & \\
\hline
\end{tabular}

Radiographic success rate for the three groups during different follow up periods 


\begin{tabular}{|c|c|c|c|c|c|c|c|c|c|c|c|c|}
\hline \multirow[t]{2}{*}{ Time } & & \multicolumn{3}{|c|}{$N H A$} & \multicolumn{3}{|c|}{ MTA } & \multicolumn{3}{|c|}{$F C$} & \multirow[t]{2}{*}{$X 2$} & \multirow[t]{2}{*}{$p^{*}$, Chi-square tes } \\
\hline & & No & Yes & $\mathrm{F}$ & No & Yes & $\mathrm{F}$ & No & Yes & $\mathrm{F}$ & & \\
\hline \multirow[t]{3}{*}{3 months } & Internal resorption & $18(100)$ & 0 & 0 & $21(100)$ & 0 & 0 & $21(100)$ & 0 & 0 & 0 & $1 \mathrm{NS}$ \\
\hline & External resorption & $18(100)$ & 0 & 0 & $21(100)$ & 0 & 0 & $21(100)$ & 0 & 0 & 0 & $1 \mathrm{NS}$ \\
\hline & Periapical RL & $18(100)$ & 0 & 0 & $21(100)$ & 0 & 0 & $21(100)$ & 0 & 0 & 0 & $1 \mathrm{NS}$ \\
\hline \multirow[t]{3}{*}{6 months } & Internal resorption & $17(94.4)$ & 0 & $1(5.6)$ & $21(100)$ & 0 & 0 & $21(100)$ & 0 & 0 & 2.37 & $0.67 \mathrm{NS}$ \\
\hline & External resorption & 15 (83.3) & $\begin{array}{c}2 \\
(11.1)\end{array}$ & $\begin{array}{c}1 \\
(5.6)\end{array}$ & $21(100)$ & 0 & 0 & $21(100)$ & 0 & 0 & 7.37 & $0.12 \mathrm{NS}$ \\
\hline & Periapical RL & 17(94.4) & 0 & $1(5.6)$ & $21(100)$ & 0 & 0 & $21(100)$ & 0 & 0 & 2.37 & $0.67 \mathrm{NS}$ \\
\hline \multirow[t]{3}{*}{12 months } & Internal resorption & $13(72.2)$ & 0 & 5 & $21(100)$ & 0 & 0 & $21(100)$ & 0 & 0 & 12.7 & $0.012 *$ \\
\hline & External resorption & $\begin{array}{c}13 \\
(72.2)\end{array}$ & 0 & $\begin{array}{c}5 \\
(27.8)\end{array}$ & $21(100)$ & 0 & 0 & $21(100)$ & 0 & 0 & 12.7 & $0.012 *$ \\
\hline & Periapical RL & $\begin{array}{c}13 \\
(72.2)\end{array}$ & 0 & $\begin{array}{c}5 \\
(27.8)\end{array}$ & $21(100)$ & 0 & 0 & $21(100)$ & 0 & 0 & 12.7 & $0.012 *$ \\
\hline
\end{tabular}

Significance level $\mathrm{P}<0.05$, * significant, $\mathrm{ns}=$ non-significant, $\mathrm{F}=$ failure

Table 4: Comparison of overall success in the study groups

\begin{tabular}{|c|c|c|c|c|c|c|}
\hline & \multicolumn{2}{|c|}{ NHA } & \multicolumn{2}{|c|}{ MTA } & \multicolumn{2}{|c|}{ FC } \\
\hline & Failure & Success & Failure & Success & Failure & Success \\
\hline Number & 5 & 13 & 2 & 19 & 5 & 16 \\
\hline$\%$ & 27.8 & 72.2 & 9.5 & 90.5 & 23.8 & 76.2 \\
\hline $\mathrm{x}^{2}$ & \multicolumn{6}{|l|}{2.312} \\
\hline P, Chi-square test & \multicolumn{6}{|c|}{$0.314 \mathrm{NS}$} \\
\hline
\end{tabular}


Table 5: Radiographic success scores during different follow up periods

\begin{tabular}{|c|c|c|c|c|c|c|}
\hline Time & score & NHA & MTA & FC & $\mathrm{X} 2$ & $p^{*}$, Chi-square test \\
\hline \multirow[t]{5}{*}{3 months } & Score 0 & 17(94.4) & $16(76.2)$ & $16(76.2)$ & \multirow[t]{5}{*}{3.96} & \multirow[t]{5}{*}{$0.86 \mathrm{NS}$} \\
\hline & Score 1 & 0 & $4(19)$ & $4(19)$ & & \\
\hline & Score 2 & 0 & 0 & 0 & & \\
\hline & Score 3 & $1(5.6)$ & $1(4.8)$ & $1(4.8)$ & & \\
\hline & Failure & 0 & 0 & 0 & & \\
\hline \multirow[t]{5}{*}{6 months } & Score 0 & $11(61)$ & 19 (90.5) & 19 (90.5) & \multirow[t]{5}{*}{15.57} & \multirow[t]{5}{*}{ 0.049* } \\
\hline & Score 1 & $1(5.6)$ & $2(9.5)$ & $2(9.5)$ & & \\
\hline & Score 2 & $1(5.6)$ & 0 & 0 & & \\
\hline & Score 3 & $4(22.2)$ & 0 & 0 & & \\
\hline & Failure & $1(5.6)$ & 0 & 0 & & \\
\hline \multirow[t]{5}{*}{12 months } & Score 0 & $10(55.6)$ & 19 (90.5) & $16(76.2)$ & \multirow[t]{5}{*}{20.87} & \multirow[t]{5}{*}{$0.008^{*}$} \\
\hline & Score 1 & $3(16.7)$ & $1(4.75)$ & $1(4.8)$ & & \\
\hline & Score 2 & 0 & $1(4.75)$ & $2(9.5)$ & & \\
\hline & Score 3 & 0 & 0 & $2(9.5)$ & & \\
\hline & Failure & $5(27.7)$ & 0 & 0 & & \\
\hline
\end{tabular}

Significance level $\mathrm{P}<0.05$, * significant, $\mathrm{ns}=$ non-significant, $\mathrm{F}=$ failure 0

Figures 


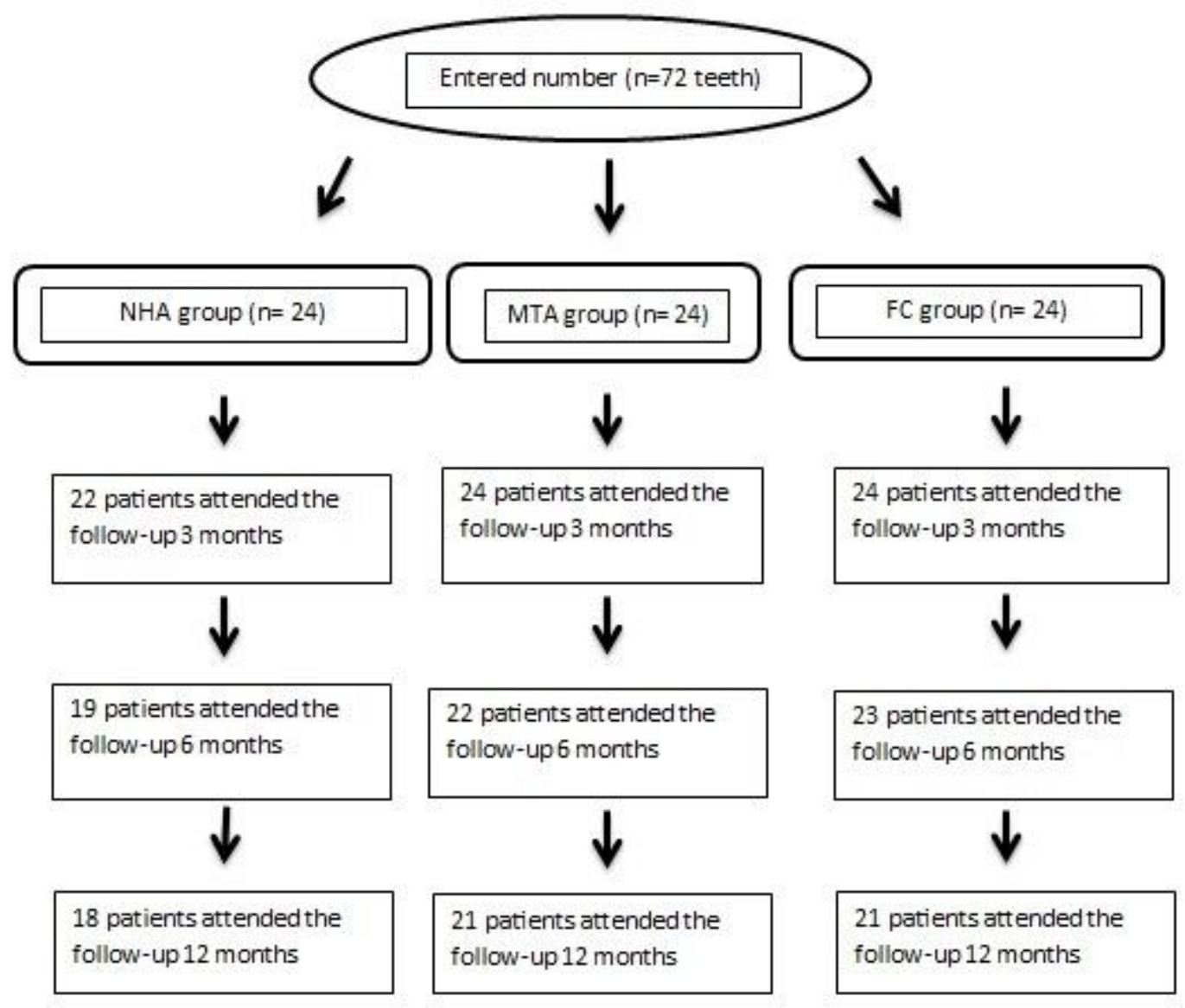

\section{Figure 1}

A consort diagram showing the study protocol

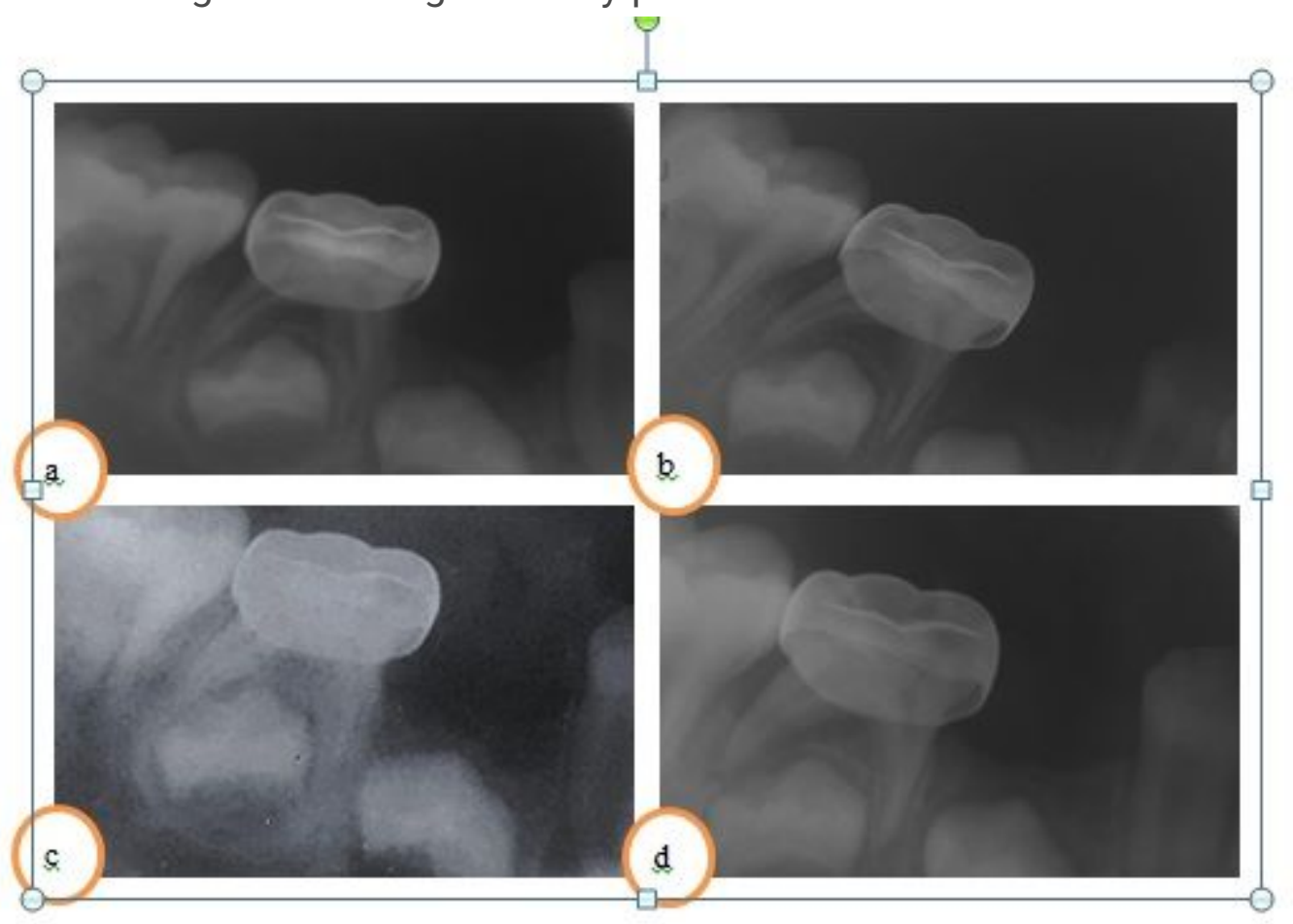




\section{Figure 2}

(NHA): Periapical radiographs of group 1: (a) Baseline (b) one month postoperative (c) 3- months postoperative (d) 6-months postoperative.

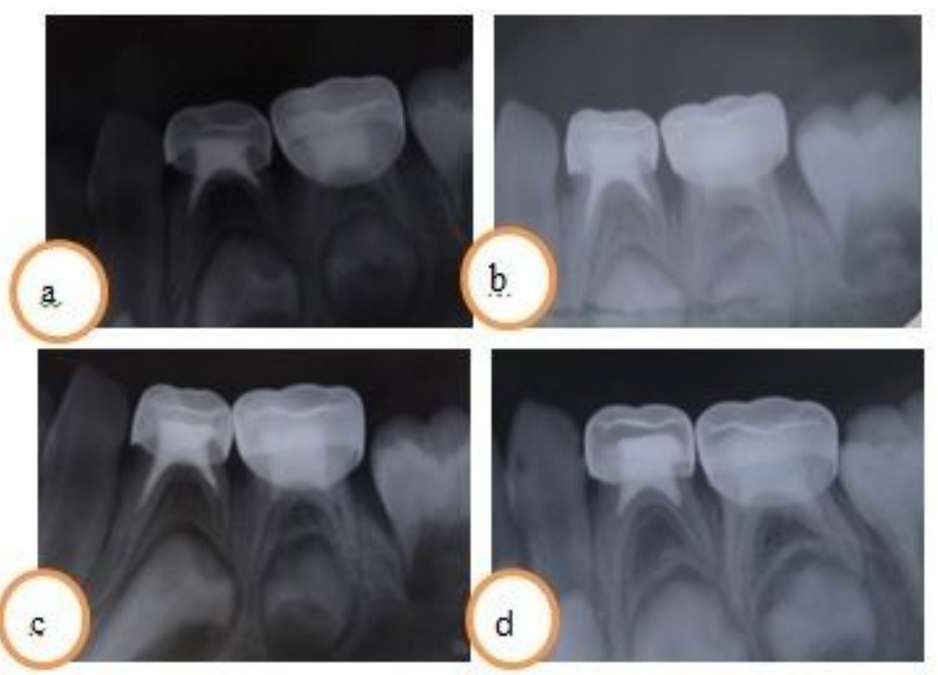

\section{Figure 3}

(MTA): Periapical radiographs of group 1: (a) Baseline (b) one month postoperative (c) 3- months postoperative (d) 6-months postoperative.

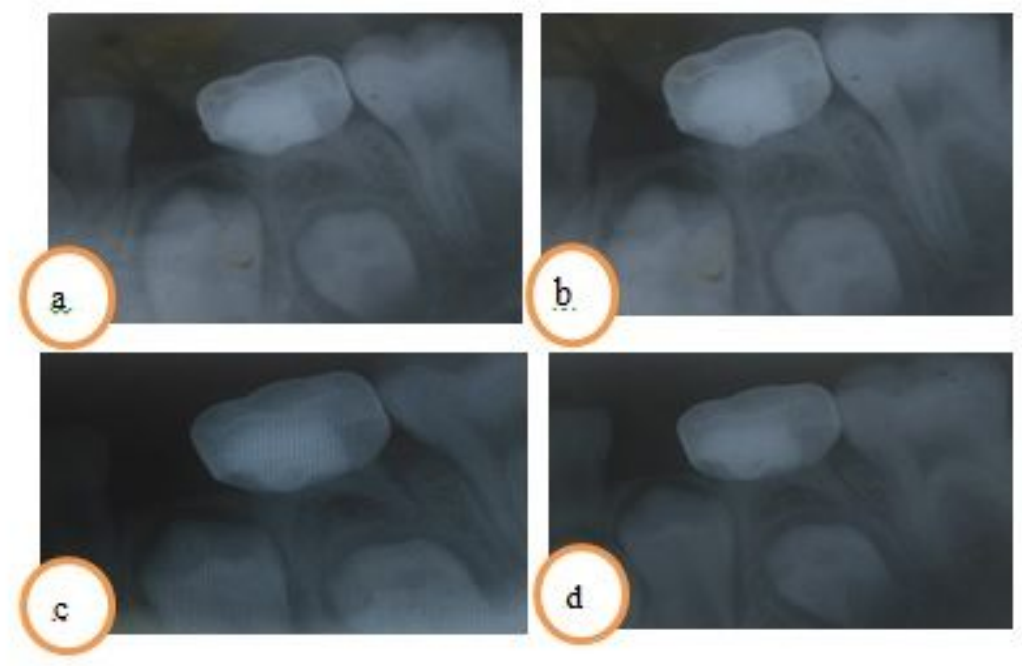

Figure 4

(FC): Periapical radiographs of group 1: (a) Baseline (b) one month postoperative (c) 3- months postoperative (d) 6-months postoperative.

\section{Supplementary Files}

This is a list of supplementary files associated with this preprint. Click to download. 
- CONSORT2010checklist.docx

- Practicelmplications.docx 